This is a self-archived version of an original article. This version may differ from the original in pagination and typographic details.

Author(s): Virta, Jukka; Hökkä, Päivi; Eteläpelto, Anneli; Rasku-Puttonen, Helena

Title: Professional identity among student teachers of physical education : the role of physicality

Year: 2019

Version: Accepted version (Final draft)

Copyright: (c) Taylor \& Francis, 2019.

Rights: In Copyright

Rights url: http://rightsstatements.org/page/InC/1.0/?language=en

Please cite the original version:

Virta, J., Hökkä, P., Eteläpelto, A., \& Rasku-Puttonen, H. (2019). Professional identity among student teachers of physical education : the role of physicality. European Journal of Teacher Education, 42(2), 192-210. https://doi.org/10.1080/02619768.2019.1576628 


\section{Professional Identity among Student Teachers of Physical Education: The Role of Physicality}

Jukka Virta $^{\mathrm{a}}$, Päivi Hökkäb ${ }^{\mathrm{b}}$ Anneli Eteläpelto ${ }^{\mathrm{c}}$ and Helena Rasku-Puttonen ${ }^{\mathrm{d}}$

Authors:

Jukka Virta

Department of Teacher Education, University of Jyväskylä, P.O.Box 35, 40014 University of Jyväskylä, Finland. Tel.: +358 44 3655566. E-mail address: jukka.virta@jyu.fi.

Jukka Virta, Licentiate in Sport Sciences, is a teacher of physical education. His research interests include teachers' social and emotional skills, teacher-student interaction and most recently teachers' professional identity.

orcid.org/0000-0002-1206-834X

Päivi Hökkäb

Department of Education, University of Jyväskylä, P.O.Box 35, 40014 University of Jyväskylä, Finland. Tel.: +358 40 8053640. E-mail address: paivi.hokka@,jyu.fi.

Päivi Hökkä, $\mathrm{PhD}$, is a senior researcher in education and adult education at the Department of Education, University of Jyväskylä. Hökkä is currently working on the REAL research project, which investigates emotions in agentic learning at work. She also leads TUNTOproject, which explores emotional agency in organizational change. She has recently conducted research and published articles on professional agency and identity, teacher education, emotions at work, and leadership in education. Her recent publications include 
articles e.g. in Journal of Teacher Education, International Journal of Educational Leadership, and Teaching and Teacher Education.

orcid.org/0000-0002-2167-6582

\section{Anneli Eteläpelto ${ }^{c}$}

Department of Education, University of Jyväskylä, P.O.Box 35, 40014 University of Jyväskylä, Finland. Tel.: +358 40 5755490. E-mail address: anneli.etelapelto@jyu.fi.

Anneli Eteläpelto, PhD (psychology) is a full Professor of Adult Education in the Faculty of Education and Psychology, University of Jyväskylä, Finland. She has widely published in academic collected editions and journals, such as Learning and Instruction, Educational Research Review, Scandinavian Journal of Education, Professional Development in Education, Journal of Teacher Education, Teaching and Teacher Education, Teaching and Teachers: Theory and Practice. She has lead several research projects, funded by the Academy of Finland, on professional learning, identities and agency. Currently she is leading Finnish Academy funded project REAL, which explores the role of emotions in agentic learning at work.

orcid.org/0000-0001-5336-7410

Helena Rasku-Puttonen ${ }^{\mathrm{d}}$

Department of Teacher Education, University of Jyväskylä, P.O.Box 35, 40014 University of Jyväskylä, Finland. Tel.: +358 50 3732119. E-mail address: helena.rasku-puttonen@jyu.fi.

Helena Rasku-Puttonen is Professor of Psychology in Education at the University of Jyväskylä. Her research interests concern learning environments, student-teacher interaction, dialogical discussions and teaching practices. 
orcid.org/0000-0001-7814-298X 


\title{
Professional Identity among Student Teachers of Physical Education: The Role of Physicality
}

\begin{abstract}
In this study, we investigate the role of physicality in the professional identities of physical education (PE) student teachers. Twenty PE student teachers participated in semi-structured interviews during their final teaching practice. Data were analysed using qualitative thematic analysis (Braun and Clarke 2006) and typologies (Patton 2002). The results showed substantial diversity in the student teachers' conceptions of physicality and the ways these conceptions were embedded in their developing professional identities. The results also brought to light criticism directed at traditional notions of the body and physicality in PE and PE teacher education (PETE). We suggest that conceptions of the body and physicality represent a central element of PE teachers' professional identity. The results also indicate a relationship between conceptions of physicality and pedagogies implemented in the future. Time and place for student teachers to discuss body-related matters should be provided in PETE.
\end{abstract}

Keywords: professional identity, student teachers, physical education, physicality, teacher education 


\section{Introduction}

The importance of professional identity for teachers has been widely acknowledged.

Educational research has suggested that teachers' identities shape the way they think, teach and project themselves into the future (Beijaard, Meijer and Verloop 2004; Lamote and Engels 2010; Pillen, Beijaard and den Brok 2013). However, few studies have investigated professional identity among physical education (PE) teachers (Keating 2017). There is no common framework for studies on PE teachers' identity, nor have many scholars sought to connect PE teachers' identity to research on the professional identity of teachers in general (e.g. Beauchamp and Thomas 2009; Eteläpelto et al. 2014). We see an urgent need to develop a deeper understanding of PE teachers' professional identity at a time of rapid societal and educational transformations, such as digitalisation and changing student-teacher relationships and work conditions in general.

Some of the main goals of PE are to promote students' well-being and help them cultivate positive relationships with their bodies (Finnish National Agency for Education 2014). In achieving this goal, teachers' own conceptions of physicality and the body are central because their notions and beliefs are reflected in their teaching (Fernández-Balboa 2001; Wrench and Garrett 2012). Traditionally, conceptions of the body and physicality in PE and PE teacher education (PETE) include instrumental and performance-oriented ideas and beliefs about the body (e.g. athletic and thin). In addition, PE teachers hold pedagogical views favouring sport over critical and inclusive ideas (e.g. Dowling 2011). Although teachers are expected to engage in professional development throughout their careers, their construction of professional identity should be supported even before their work begins-in other words, in teacher education (Thomas and Beauchamp 2011). To support the formation of positive relationships with the body in PETE and the teaching of PE, researchers should develop sound understanding of the ways in which conceptions of the body are integrated 
into the developing professional identities of PE student teachers. In the present study, we investigate the role of physicality in these developing professional identities.

\section{Professional identity}

Professional identity has been studied widely. For example, researchers recently examined professional identity among teacher educators (Hökkä and Eteläpelto 2014; Murray, Swennen and Shagrir 2009), primary school teachers (Blackmore, Howard and Kington 2018; Erickson and Pinnegar 2017; Pappa et al. 2017; Weiner and Torres 2016), preservice primary school teachers (Ó Gallchóir, O’Flaherty and Hinchion 2018; Popper-Giveon and Shayshon 2017; Ruohotie-Lyhty and Moate 2016) and secondary teachers (Vähäsantanen 2015).

There are different understandings of professional identity (e.g. Beauchamp and Thomas 2009; Beijaard, Meijer and Verloop 2004). Current opinion views it broadly as dynamic in nature yet with a thread of continuity. It is also commonly seen as comprising both social and individual dimensions and negotiated in the interactions of individual resources and their social environment (Akkerman and Meijer 2011; Beauchamp and Thomas 2009; Beijaard, Meijer and Verloop 2004; Canrinus et al. 2011; Eteläpelto et al. 2014). The significance of the individual in the construction of professional identity is highlighted by discussions on personal reflection, narrative elements (Beauchamp and Thomas 2009) and agency (Eteläpelto et al. 2013). In contrast, external factors become prominent when the discussion turns to social and material environments, including work and life experiences (Day and Kington 2008).

Teachers' professional identity is understood to encompass values, emotions, ethical commitments, future aspirations, professional knowledge and competencies (Beauchamp and Thomas 2009; Beijaard, Meijer and Verloop 2004; Eteläpelto et al. 2014). Professional 
identity construction takes place throughout teachers' careers (Day 2012; Vähäsantanen et al. 2008) but is especially pertinent during the early years of teaching when tensions in professional identity are common (Eteläpelto, Vähäsantanen and Hökkä 2015; Pillen, Beijaard and den Brok 2013). The construction of professional identity usually is a slow process; hence, the negotiation of professional identity should be supported in teacher education before work even commences (Thomas and Beauchamp 2011). Pedagogical initiatives during teacher training have been found to produce positive outcomes for student teachers' professional identities (Izadinia 2013), including a stronger sense of agency and self-awareness.

In this study, professional identity is viewed as an individual's conception of oneself as a professional subject based on one's future expectations, professional and personal history and sociocultural and sociomaterial resources (Beijaard, Meijer and Verloop 2004; Day 2012; Eteläpelto et al. 2014; Lamote and Engels 2010). In the occupation of PE teaching, the embodied nature of identity (see Archer 2000; Tinning 2010) cannot be avoided, and the teacher's body, movement, skills and beliefs about the body become part of professional identity. Thus, in this study, we investigate professional identity based on PE student teachers' conceptions of the body. We use the terms the body and physicality concurrently to refer to both the physical body and its physical qualities, such as fitness, skills and physical appearance.

\section{Professional identities of PE teachers}

Few studies have addressed PE student teachers' professional identities. Keating and colleagues (2017) found only fourteen studies of professional identity among preservice PE specialists and generalists published between 1990 and 2014. Most of these studies were 
qualitative, examining professional identity from different theoretical perspectives (e.g. sociocultural and poststructural) and disciplines (e.g. sociology and psychology). These studies focused on the factors contributing to the development of professional identity, most prominently PETE, and individual students' qualities, such as personal sporting background.

More recently, González-Calvo, and Fernández-Balboa (2018) investigated the factors determining the quality of relationships between PE teachers and students' families and these relationships' influence on professional identity during the early years of teaching. The study identified factors that positively and negatively affect teacher-parent relationships and professional identity. Among the negative influences are scarce work opportunities, obligation to locate to a different school annually and family prejudices against PE. Teachers' commitment, persistence and self-reflection and parents' acknowledgement of teachers' work are positive influences. The emergence of PE teacher identity is only evident after few years of working as PE teachers.

In another study on PE teachers' identity construction, a range of spaces (e.g. schooling, PETE, sport and family) and discourses (e.g. relationships to sport, physical activity and country life) from teachers' past and present provide resources for constructing narrative identities as PE student teachers (Wrench 2017). This process suggests that the construction of professional identity is not confined to the context of teacher education (Wrench 2017), which nonetheless remains widely acknowledged as important in, for example, the construction of professional knowledge ( e.g. Alves et al. 2012; Keating et al. 2017). Da Cunha, Batista, and Graça (2014) also identified major discursive themes in PE student teachers' construction of professional identity: classroom practice, colleagues' social recognition, a sense of mission and learning situations, such as acquiring practical knowledge. Emotions have been also been reported to support and guide the construction of professional identity (Alves et al. 2018). 
However, studies integrating PE student teachers' body conceptions and professional identity remain scarce, and it can be argued that PE teachers' professional identities traditionally centre on sports knowledge and skills rather than broader educational issues. Physical performance and mastery of specific sports are valued over critical thinking (Capel 2007; Dowling 2006, 2011; Larsson 2009). Physical fitness and the ability to demonstrate skills associated with various sports are prioritised (Dowling 2011; Larsson 2009; Thorburn 2014). Furthermore, PE traditionally emphasises the development and measurement of physical attributes, such as stamina, and the acquisition of technique through drills and repetition (Tinning 2010).

The normative body conceptions in PE and in PETE include being thin, fit, skilled, athletic and muscular (Fisette 2015; Fletcher 2012; MacDonald 1993; Sirna, Tinning and Rossi 2010; Spittle et al. 2012). Here, it is worth noting that physiological discourses of the body dominate the PE field (Tinning 2010), and PETE students have not always recognised or challenged the socially constructed nature of the appropriate, normative and healthy PE teacher's body (Garrett and Wrench 2012; Wrench and Garrett 2015). Although this set of norms has been criticised for decades, it can be claimed that the instrumental concept of the body separating the mind from the body, remains dominant in PE and PETE (Tinning 2010; Wright 2000).

Despite this somewhat static picture of PETE, critical voices have regularly proposed alternative professional cultures and identities (Fernandez-Balboa 1997; Kirk, MacDonald and Tinning 1997; MacDonald 1993; Tinning and Glasby 2002; Wright 2000; Wrench and Garrett 2015) and questioned the applicability of the traditional, performance-oriented PE teacher identity to today's schools (e.g. Dowling 2011; Garrett and Wrench 2012). One can point, for example, to digitalisation and changing student-teacher relationships and work conditions in general. The most recent Finnish national PE curriculum, implemented since the 
autumn of 2017, also calls for joy, playfulness and enjoyment accompanied by accepting attitudes towards bodies (Finnish National Agency for Education 2014). In PE teaching, in particular, the teacher's concept of the body is critical and affects the teacher's attitude to students' bodies, selection of pedagogies and body-related discourses maintained (see Fernández-Balboa 2001; Garrett and Wrench 2012; Wrench and Garrett 2012). Implementing the kind of PE mentioned in the new Finnish PE curriculum, requires versatile PE teachers who can relate to students from a variety of social and cultural backgrounds (cf. Dowling 2011; Dowling and Kårhus 2011).

A limited number of studies has considered PE student teachers' professional identity and especially their conceptions of physicality as part of professional identity. In the present study, therefore, we investigate the role of physicality in the developing professional identities of PE student teachers. This lead us to frame the following research questions:

- What kinds of conceptions of physicality and the body can be identified?

- How are conceptions of physicality and the body embedded in the developing professional identities of PE student teachers?

\section{Methods}

\section{The research context}

The Finnish teaching profession traditionally has performed well in international comparisons (Simola et al. 2017). The Finnish PETE entrance examination is quite rigorous; only 3-8\% of applicants have been accepted annually in recent years (Kalaja 2012). The exam consists of a written test measuring academic skills, tests of motor abilities and a micro-teaching situation. There are annual quotas for female and male students, although legislation does not enforce gendered teaching groups. PETE courses in Finland are equivalent to master's level studies, 
and the degree qualifies candidates to teach PE at a range of levels within the education system from elementary schools to secondary education. The programme includes pedagogical studies, language and communication studies, teaching practice, health education (or another minor subject), skills in a range of sports and a master's thesis.

Teaching practices are integrated into studies throughout the Finnish PETE programme. During the undergraduate programme (years 1-3), students participate in courses familiarising them with teaching and PE teachers' work in school contexts through a combination of observations, written assignments and practice teaching in small groups. Teaching practices are also covered in various sport-specific courses. The total amount of teaching practice is 10-20 hours and varies annually among groups and schools. The master's programme (years 4-5) consist of a range of courses in sports, including individual lessons of practice teaching. More extensive teaching practice (15 ECTS credits, approximately 35-45 hours of individual teaching) is divided into three periods conducted at different school contexts and levels (e.g. lower, upper-secondary, vocational and high schools).

\section{Data collection and participants}

The research participants were twenty PE student teachers (twelve women and eight men) conducting their final teaching practice in a master's degree program in PE at a Finnish university. In the selection process, fifty PE student teachers attending their final teaching practice were introduced to the research agenda at the opening event of the spring semester. The first author explained the study aim, purpose and ethical principles and asked for volunteers for the study. Twenty of the fifty student teachers volunteered to participate.

The first author later contacted these students through email to arrange semistructured interviews (see e.g. Brinkmann and Kvale 2015), which are a widely used method of inquiry in studying professional identity and a sound method to investigate conceptions, in 
this case, student teachers' conceptions of their physicality and themselves as PE teachers. The interview questions were informed by conceptions of professional identity and included themes such as personal and professional history, future career aspirations, teaching aims and basic principles (e.g. values and goals), gender and the body in teaching PE and influential experiences during teacher training. The participants had varying experiences in teaching PE. Some had worked in schools as substitute PE teachers for up to two years, and most had been involved in some kind of sport-related work, such as coaches and sport camp instructors. However, most student teachers' experience of PE teachers' work was limited to a few hours of substitute teaching and teaching practice within the PETE programme.

The interviews were conducted in neutral locations, such as student study rooms in the university library. The interviewees were informed that participation in the study was voluntary, and they could withdraw at any time. Data would not to be used outside the research group, and the research participants would remain anonymous. The individual interviews lasted from approximately forty minutes to almost two hours. The overall duration of the interviews was twenty-one hours. The questions varied from open-ended to more focused items concerning the interviewees' conceptions, experiences and opinions on a number of preliminary themes selected in advance. These themes were intended to be exploratory in nature, and it was anticipated that they would be modified, or new themes would emerge in the light of the interviews and analysis (see the data analysis section).

The first author, an experienced PE teacher who was not part of the PETE staff, conducted the interviews. The similarity between the backgrounds of the interviewer and the interviewees provided a good basis for casual interactions and made it easy for the researcher to relate to the students' views. The interviews were informal and conversational. Despite the preselected themes, there was freedom to pursue any matter of interest that emerged during the interviews. The study was conducted in accordance with the national ethical guidelines of 
Finnish National Board on Research Integrity (2009). The participants were also given an opportunity to read the manuscript before publication.

\section{Data analysis}

The data consisted of the interviews transcribed verbatim by the first author (360 pages, 12 point Times New Roman font, 1.5-inch line spacing). The data were subjected to qualitative thematic analysis (Braun and Clarke 2006). The phases of the analysis were as follows. First, all the data were read, and passages related to physicality were extracted and then condensed according to the meanings in the text, paying attention to the context. In the next phase, the condensed extracts were assigned preliminary labels in an inductive, data-driven manner. The extracts were grouped together according to their labels, which were revised as appropriate. This process yielded seven themes (e.g. 'appropriate PE teacher's body') related to the phenomenon of interest (conceptions of physicality and the body) and illustrative of the differences and similarities apparent in the data. The themes were then reviewed to determine whether they matched the labelled extracts and the overall dataset. The themes were further refined and defined, and the main content or the 'essence' of each theme was identified.

To refine the various understandings of physicality found in the data, we followed Patton's (2002) guidelines on typological methods. Typologies are abstractions and interpretations of data intended to illustrate different features of a particular phenomenon. They divide aspects of the topic of interest (e.g. an individual's conceptions of an appropriate PE teacher's body) into parts along a continuum and form a particular combination of features that result in a distinct typology. Nevertheless, typologies are not exhaustive or systematic taxonomies as exist in, for example, the natural sciences.

In this study, typologies were formulated based on the variations (differences and similarities) within each theme and demonstrated the different aspects of physicality in each 
theme. By this means, we arrived at five orientations (typologies) describing the integration of conceptions of physicality into the PE student teachers' professional identities. Each orientation was named after its defining feature. It should be noted that the orientations were abstractions and did not necessarily exist in a 'pure' form in any individual student teacher. The analysis process was iterative and inductive.

\section{Findings}

The analysis revealed seven themes and five orientations: performing, tensional, pedagogical, experimenting and holistic (see Table 1).

\section{The performing orientation}

In the performing orientation, physicality (a fit physical appearance, physical skills and physical fitness) is emphasised as part of one's professional identity. It is crucial that the teacher exemplify a sporty appearance and a high level of fitness and is capable of

demonstrating various physical skills. A skilful, fit body conveys credibility and confidence in teaching. One student teacher explained: 'If you're in bad shape and cannot demonstrate, you're not very convincing as a teacher' (Interview, Sophie). Another student stated: 'The way I see it, it's a bit like, the bigger the muscles I have, the better teacher I am' (Interview, John).

Similarly, this orientation exhibits conditional acceptance of the body, and the appropriate PE teacher's body is viewed as fit, slim, muscular, physically coordinated and able-bodied. Movement is understood in relation to a range of sports and techniques, as demonstrated in the following extract: 'If you want them to do a double backflip, you better do it yourself first' (Interview, Mia). The emphasis on good physical appearance is reflected 
in another extract: 'The body is very much in the centre these days - the fitness trend, you know, judging people by the way they look' (Interview, Mark).

This orientation has a very narrow definition of the appropriate PE teacher's body, leaving little room for variety. It also puts considerable emphasis on a well-functioning, presentable body and the ability to demonstrate various skills, which may require renegotiation of professional identity in the future when age may restrict the skills teachers can demonstrate. The body conceptions in this orientation reflect conformity to traditional normative body ideals in PE and PETE requiring teachers to be fit, thin and skilled.

\section{The tensional orientation}

In the tensional orientation, as in the performing orientation, physicality is important to professional identity, and a capable body lends credibility to the PE teacher, who should exemplify positive attitudes towards exercise through a fit body. However, conceptions of body in the tensional orientation are characterised by conflict between conforming to and rejecting body-related norms in PE while accepting oneself. The study setting of PETE, in which everyone seems to be skilled and in good shape could easily distort the idea of a 'normal' body. Comparing oneself to other students results in pressure to exercise to be fit. The normative body is thin and muscular, as noted by Darrell: 'The idea of the normal body of a regular Finnish man is really distorted in the men's locker room. It seems like everybody is in peak condition'.

Such pressure also comes from individuals' own demands and expectations, which make it even more difficult to resist external pressure: 'You don't always realise, especially when you're younger, that you can be a good person [and a teacher] without being super fit' (Interview, Cathy). Eating disorders and excessive training, both reported by the students, can 
be understood as resulting from attempts to fit in and adapt to the normative body ideals in PETE.

It's true there are a lot of eating disorders, and everybody thinks about how they look, and everybody does a lot of exercise. And if you don't, you feel like a loser and then you have to go and train too. (Interview, Erica)

The tensional orientation, as its name suggests, includes recognition of these tensions and resistance to and even criticism of the pressure to conform. In the following extract, a female student teacher exhibits her recognition of the normative PE body and reluctant adherence to the norm alongside unwillingness to submit to it entirely:

Sometimes it gets overly feminine, and it's really frustrating. I mean, why should I be thin just so that the girls will appreciate me? On the other hand, the trend right now is towards a more muscular body, which comes more naturally to me, and the girls kind of need me to show an example. (Interview, Natalie)

Natalie's statement illustrates criticism of the norm upheld by traditional PETE culture that the PE teacher's body should be thin and muscular.

\section{The pedagogical orientation}

In the pedagogical orientation, physicality is central to PE teachers' professional identity. Its importance, though, is related to the ability to teach effectively: if one is a good teacher, there is no need to have an exemplary body, be in peak condition or know every sport. Some interviewees mentioned: 
I don't think PE teachers should be like, super fit or something, or know every sport there is. (Interview, Will)

You can be a really good teacher and not be super fit, but physical fitness and appearance, they still kind of show to the students what we're doing here. (Interview, Sarah)

An athletic appearance and the ability to learn and demonstrate different skills give teachers credibility: good teaching is not enough if one is overweight. Conversely, convincing physicality alone does not make one a good PE teacher. Nevertheless, teaching PE does require some level of physical fitness (e.g. the ability to stand and walk for long hours), so it is important to be fit enough to do the work of a PE teacher:

Being in good shape and doing a lot of exercise, it kind of gives you confidence to teach those things. (Interview, Vera)

You want to be in good condition just to be able to do this work. (Interview, Tina)

In this orientation, the conceptions of the body are more accepting of differences than the previous orientations, but nevertheless, certain limits apply. In this orientation, a 'normal'that is, neither overweight nor anorexic — body is seen as sufficient for PE teachers.

Well, it does matter, I mean, whether you're credible - if you're anorexic or a bit chubby, and at the same time, you're saying that it's so important to take care of yourself, eat well, and exercise. (Interview, Laura) 
I think a PE teacher should have a more or less normal body and be sort of sporty, but the categories of what's normal are pretty wide. (Interview, Sally)

One can always question the notion of 'normal' in this orientation. The interviewees demonstrated relatively accepting body conceptions and reported being satisfied with their bodies. However, an overweight body is still thought to be inappropriate for PE teachers.

The body conceptions of this orientation include recognition of the peer pressure and normative body ideals related to PE teaching. However, these norms are not unconditionally accepted. Having a fit body is a positive asset but is not consciously pursued. Rather, an athletic appearance is believed to result from an active lifestyle:

I'm quite happy that I'm not overweight, but in the end, it's no big deal. It's sort of like, that's what you get if you're active and do a lot of exercise, but it's not the main point. (Interview, Luke)

\section{The experimenting orientation}

In the experimenting orientation, physicality (physical appearance, skills and fitness) forms part of student teachers' developing professional identity. However, what is considered to be essential are an open, exploring attitude, learning from mistakes and the ability to instruct rather than the mastery of specific skills, an exemplary body or physical fitness. The conceptions of the body in this orientation are slightly more accepting than in the previous orientations, and overweight bodies are seen as acceptable for PE teachers. As noted by Shawn: 'I used to have a teacher who had a good-sized belly, but he's still one of the best teachers I've ever seen'. 
Openness, creativity, playfulness and experimentation with different movements characterise the idea of exercise in this orientation. The body is seen as a tool for learning; there is not necessarily a single correct way of doing things. Making and learning from mistakes are encouraged:

It's very important to make mistakes. That's how you learn and find something new. And the idea that people have-it's really silly that they think they don't know how to do something if they don't know the 'right way' of doing it. You can do like ten different kinds of cartwheels without doing the one they do in gymnastics. (Interview, Alec)

In this orientation, the normative PE body ideal is recognised but not unconditionally pursued. A sporty physical appearance is seen as a role that can be assumed if needed: 'You kind of take a role, that teachers of PE have a certain look, and you go with the flow yourself, and it's ok, a certain kind of role' (Interview, Ben).

Alec's statement indicates a certain relationship between body conceptions and the applied pedagogies: when there is curiosity about and acceptance of the body, pedagogies that embrace acceptance and diversity in motion will follow. The creative, playful notion of movement in this orientation implies distancing from the traditional concept of motion in PE and PETE emphasising mastery of sport-specific skills.

\section{The holistic orientation}

In the holistic orientation, physical appearance, skills and physical fitness are seen as secondary elements of a PE teacher's professional identity. As expressed in the following comment: 'In my opinion, a PE teacher could just as well be in a wheelchair or overweight so 
long as she/he is a good teacher' (Interview, Peter). In this orientation, what is considered important is acceptance of the body and being an example to students of such acceptance. For instance, Simone, a female student, mentioned a woman she had encountered while working as a personal trainer. The woman came to her with a picture from a fitness magazine and said, 'This is what I want to look like'. Simone's opinion was that she, in contrast, wanted to 'make people see and recognise how different movements feel in the body'. A strong experience of one's own motion and body gives teachers confidence:

Having a strong experience of my own motion and movement, that helps me and makes me more confident in my teaching, so I don't feel a need to slip into any role or pretend to know such and such a thing. (Interview, Jessica)

In the holistic orientation, the body is accepted unconditionally. Aging, overweight and lessfunctional bodies are all considered to be normal. A well-functioning body is not taken for granted. These accepting conceptions of the body are reflected in Nelly's comment: 'Maybe I'm a bit more tolerant than the average student, like when thinking about what is healthy or not. As if you couldn't be healthy if you're overweight'.

The understanding of motion in this orientation involves becoming aware of one's body and experiencing different movements in an individual way regardless of age, gender or skills: 'To me, it's important not just to do but also to listen to the body and how you're feeling so that it helps you to understand your body and be aware of the changes' (Interview, Nelly). A similar point was made in relation to gender: 'I want to encourage people to be what they are, maybe find that they can be strong and powerful in their own movements, and it's not related to one's gender' (Interview, Shelley). 
Here, too, these extracts suggest a relationship between positive body conceptions (accepting and listening) and the pedagogies to be implemented (body consciousness and feeling vs. performing the body). The holistic orientation, with its broad conception of the acceptable body and emphasis on motion as individually experienced, contains an implicit criticism of the traditional body conceptions in PE culture-conceptions that privilege instrumental attitudes towards the body and narrowly define the acceptable body.

[Table 1 here]

\section{Discussion and conclusions}

This study reveals substantial diversity in the PE student teachers' conceptions of physicality and the body and the ways these conceptions are embedded in their developing professional identities. The analysis identifies five orientations towards the integration of physicality into professional identity, labelled as performing, pedagogical, experimenting, tensional, and holistic orientations. The student teachers' conceptions of the body within these orientations show varying degrees of acceptance of the body, understandings of movement ranging from technique-oriented to experiential views, and a variety of views on the acceptable PE teacher's body ranging from slim and athletic to overweight. Conceptions of the body, physical appearance, skills and fitness are found to form essential elements in PE teachers' professional identities. Nevertheless, the importance of physicality ranges from centrally significant to less meaningful, and physicality has relationships with other qualities, such as professional knowledge.

PE teachers' identities can be strongly based on the ability to participate in and demonstrate various skills (see Fisette 2015; Wrench and Garrett 2015), and pupils can 
perceive these abilities as giving PE teachers credibility (Ramos and McCullick 2015). It is rightly argued that PE teachers should have personal engagement with different sports, not only theoretical knowledge (Johnson 2015). However, a professional identity based on a performing body is very vulnerable to, for example, injuries, which can lead to professional crises and renegotiation of professional identities (Fisette 2015). It should be noted that the PE culture has been criticised for overlooking broader educational issues and concentrating on sport-specific didactics and skills (Capel 2007; Dowling 2006, 2011; Larsson 2009). Of course, these issues are by no means mutually exclusive: meaningful engagement does not rule out varied pedagogical practices or good understanding of PE-related theoretical topics. Most interviewees recognise the existence of traditional normative body ideals in PE (see Webb et al. 2008; Wrench and Garrett 2015) and notions of the 'stereotypical PE teacher' (Spittle et al. 2012). Some participants more or less willingly accept these views and conform to their demands, whereas others do not even see them as pressures to conform to because they are in accordance with the participants' own values. Some have reservations about these normative body ideals but feel no strong pressure from them. Other participants, though, express that they struggle to resist such norms. Still others reject the normative ideals and demonstrate strong personal commitment to more holistic, accepting body relationships. Tensional body-talk was also noted in a study by Garrett and Wrench (2012), in which PE student teachers exhibit reluctance to conform to existing body norms while still desiring to be more muscular or weigh less. The student teachers will eventually encounter overweight and obese students in their work. The notion of a strictly prescribed, acceptable PE teacher's body might not itself imply disapproval of overweight students but does raise questions about potential obesity bias (see Doolittle et al. 2016) as teachers' identities and beliefs cannot be separated from their teaching and the pedagogies they apply (Fernández-Balboa 2001). 
The experimenting, tensional and holistic orientations embed implicit criticisms directed at the traditional technique-oriented notion of motion (Tinning 2010), normative body ideals (Fisette 2015; Fletcher 2012; Macdonald 1993; MacDonald and Kirk 1999; Sirna, Tinning and Rossi 2010; Spittle et al. 2012) and instrumental relationship to the body in PE and PETE (Wright 2000). The reservations expressed appear to represent potential for change in PE student teachers' conceptions of the body and professional identities, shifting away from traditional body ideals and conceptions in PE and PETE. The PE student teachers demonstrate agency in constructing their professional identities and views of the body, which become apparent in the data as they think about the body in different ways, try new kinds of movement and apply teaching practices that leave space for experimentation, reflection and listening to the body. It also involves talking about the body in language that avoids traditional norms and constitutes verbal resistance to oppressive, potentially harmful ways of relating to the bodies of teachers and students (cf. Cliff and Wright 2010). Student agency has been identified as a key element in challenging and changing existing beliefs and identities during teacher training (Keating et al. 2017).

The holistic orientation is especially different from the PE teacher's traditional identity as performer. Indeed, it bears closer resemblance to the teacher identity implied in the Finnish national PE curricula, calling for accepting attitudes towards the body and joy and pleasure in movement (Finnish National Agency for Education 2014). Here, there are similarities to the 'alternative' teacher identities described by Wrench and Garrett (2012), who found that students can create teacher subjectivities embracing inclusiveness despite a context stressing performance-oriented discourses.

The performing and pedagogical orientations represent the reproduction of current or traditional PE culture and norms. These orientations include some characteristics previous studies have noted as belonging to PE culture: the centrality of a thin, muscular body in 
professional identity and uncritical views of pedagogy and corporeality (Dowling 2006, 2011; Garrett and Wrench 2012; Tinning 2010; Wrench and Garrett 2015).

The results regarding the experiential and holistic orientations suggest a relationship between the PE student teachers' body conceptions and the pedagogies they will implement in the future (see Fernández-Balboa 2001). Hence, if the prevailing relationship to the body involves acceptance and listening without making comparisons or insisting on top physical performance, one could expect PE pedagogies to become more tolerant of different bodies. Of course, this does not exclude learning specific sports or techniques, but it does lay the foundation for PE teaching as a holistic activity in which students can participate and feel accepted regardless of their skills and body types. Accepting and acknowledging differences in PE pupils' physicality becomes increasingly important with the current educational trend in Finland towards the integration and inclusion of pupils with special educational needs into regular classes. The new PE national curricula also calls for joy of movement and a positive relationship towards one's body (Finnish National Agency for Education 2014). PETE, therefore, should address issues concerning physicality in PE teacher education as heterogeneous physical activity, motivation and skills among students is a reality future PE teachers will face. In addition, PETE recruitment in Finland emphasises candidates' physical capabilities but not to the same extent their attitudes and pedagogical thinking, although there is an annual quota for one student with a physical or sensory disability. As part of entrance exams, interviews could provide opportunities to evaluate candidates' views on inclusion and physicality. This might also encourage teacher candidates with disabilities to apply. Furthermore, at least in elementary school, flawless physicality in PE teachers is not essential for student learning and effective teaching (Bryant and Curtner-Smith 2008).

Overall, in the orientations describing the integration of physicality conceptions into professional identity, the aging, overweight or nonfunctional body is mentioned rarely, a 
finding in line with the general PE body-related discourse reported in other studies (e.g. Garrett and Wrench 2015). This can be partly explained by the youth of the students, who are at an age when a well-functioning, unproblematic body can be taken for granted. For some students, physicality may have been such a natural part of their professional identity that they are simply unable to articulate or analyse its connection with the work of PE teachers. This attitude becomes apparent in the difficulties some students experience describing the significance of the body in their professional identity as prospective PE teachers. The lack of such descriptions may also have been due to the interviewees' lack of experience performing the work of teacher. Nevertheless, the scant attention to the 'nonoptimal' body reflects the criticism of PE for its unwillingness to challenge or encourage critical thinking and resistance to the 'cult of the body' (i.e. the centrality of physical appearance) in Western cultures (Tinning and Glasby 2002).

Overall, this study highlights the considerable diversity of PE student teachers' conceptions of the body, physicality and ways of embedding these conceptions in their developing professional identities. The results suggest a relationship between PE student teachers' body conceptions and the pedagogies they desire to implement in the future (cf. Fernández-Balboa 2001). It should be borne in mind that the orientations are abstractions and do not necessarily exist in a 'pure' form in any individual student teacher. Nevertheless, the connections between body concepts and pedagogical applications are also evident at an individual level.

The orientations embed criticism of traditional PE body culture alongside considerable diversity and criticism in their conceptions of the body. In this sense, the picture that emerged is somewhat different from what one might expect based on previous research on PE teachers' professional identities and body concepts (e.g. Dowling 2006, 2011; Wrench and Garrett 2012, 2015). Perhaps this suggests the emergence of a 'new' generation of PE 
student teachers in Finland whose professional identity does not necessarily incorporate a strong link between performing exemplary physicality and 'being a PE teacher'.

The impact of PETE in the development of these critical stances should not be overlooked, even if at present, it seems somewhat marginal. Nevertheless, similar findings were reported by Garrett and Wrench (2012), who found that despite the dominant discourses on PE student teachers, some can construct 'different' teacher identities. Sirna, Tinning and Rossi (2010) similarly reported that PE student teachers challenge PE community norms.

Research on PE teachers' professional identity has been very limited relative to research on other areas of schools (Keating et al. 2017). In this paper, therefore, we aim to connect studies on physicality and PE teachers' professional identity to general educational research on teachers' professional identity (e.g. Beauchamp and Thomas 2009; Beijaard, Meijer and Verloop 2004). As a conclusion, we suggest that conceptions of the body and physicality should be regarded as major elements in the construction of PE student teachers' professional identities. On a practical level, the study results stress the importance of providing theory, opportunities and arenas during PETE to explore body-related issues. This would ensure the future PE teachers' awareness and ability to critically assess and discuss various body related phenomena such as overweight, eating disorders and distorted body images of young people present in schools.

A study limitation is that only twenty of the fifty students attending the final teaching practice course participated in the study. One must be cautious when generalising the findings, bearing in mind also that PETE contexts vary internationally. In addition, potential alternative orientations were also formulated during the analysis process. Nevertheless, we maintain that the orientations chosen are highly representative of the range of views expressed, illustrating the essential differences and similarities in the data. Furthermore, the chosen methodology might not have permitted as deep an investigation of the experiential 
side of physicality as multiple in-depth interviews, focus groups or a narrative approach. The methodology applied also did not do justice to student teachers not as articulate or self-aware of their understanding of physicality. Despite these limitations, the study contributes to a fuller understanding of the phenomenon of body conceptions as an element of PE student teachers' professional identity.

Future research can be expected to explore the various processes involved in the construction of professional identity and conceptions of the body during PETE. Moreover, it is important to conduct observations to examine the relationships between the body conceptions of in-service teachers of $\mathrm{PE}$ and the pedagogical practices applied in PE teaching. Aspects relating to the personal dimensions of identity, such as gender and experiences outside formal teacher training, also have strong presences in the data, and these issues will be studied in future papers.

\section{Acknowledgements}

This study was funded by the Rector of the University of Jyväskylä. The authors would like to thank the PE student teachers for their participation. We would also like to thank Donald Adamson for polishing the language of this manuscript.

\section{Disclosure statement}

No potential conflict of interest was reported by the authors.

\section{References}


Akkerman, S. A, and P. C. Meijer. 2011. “A Dialogical Approach to Conceptualizing Teacher Identity." Teaching and Teacher Education 27 (2): 308-319. doi:10.1016/j.tate.2010.08.013.

Alves, M., MacPhail, A. Queirós, and P. Batista. 2018. "Becoming a Physical Education Teacher during Formalized School Placement: A Rollercoaster of Emotions.” European Physical Education Review. doi:10.1177/1356336X18785333.

Alves, M., Pereira, A., Graça, A. and P. Batista. 2012. "Practicum as a Space and Time of Transformation: Self-narrative of a Physical Education Pre-service Teacher." USChina Education Review B 7: 665-674.

Archer, M. S. 2000. Being Human: The Problem of Agency. Cambridge: Cambridge University Press.

Beauchamp, C., and L. Thomas. 2009. "Understanding Teacher Identity: An Overview of Issues in the Literature and Implications for Teacher Education." Cambridge Journal of Education 39 (2): 175-189. doi:10.1080/03057640902902252.

Beijaard, D., P. C. Meijer, and N. Verloop. 2004. 'Reconsidering Research on Teachers' Professional Identity." Teaching and Teacher Education 20 (2): 107-128. doi:10.1016/j.tate.2003.07.001.

Blackmore, K., Howard, C., and A. Kington. 2018. “Trainee Teachers' Experience of Primary Science Teaching, and the Perceived Impact on Their Developing Professional Identity." European Journal of Teacher Education. doi:10.1080/02619768.2018.1462330.

Braun, V., and V. Clarke. 2006. "Using Thematic Analysis in Psychology.” Qualitative Research in Psychology 3 (2): 77-101. doi:10.1191/1478088706qp063oa. 
Brinkmann, S. and S. Kvale. 2015. Interviews: Learning the Craft of Qualitative Research Interviewing. London: SAGE.

Bryant, L. G. and M. D. Curtner-Smith. 2008. “Impact of a Physical Education Teacher's disability on Elementary Pupils' Perceptions of Effectiveness and Learning". Adapted Physical Activity Quarterly 25: 118-131.

Canrinus, E. T., M. Helms-Lorenz, D. Beijaard, J. Buitink, and A. Hofman. 2011. "Profiling Teachers' Sense of Professional Identity.” Educational Studies 37 (5): 593-608. doi:10.1080/03055698.2010.539857.

Capel, S. 2007. "Moving beyond Physical Education Subject Knowledge to Develop Knowledgeable Teachers of the Subject." The Curriculum Journal 18 (4): 493-507. doi:10.1080/09585170701687936.

Cliff, K., and J. Wright. 2010. "Confusing and Contradictory: Considering Obesity Discourse and Eating Disorders as They Shape Body Pedagogies in HPE.” Sport, Education and Society 15 (2): 221-233. doi:10.1080/13573321003683893.

da Cunha, M. A., Batista, P. and A. Graça. 2014. "Pre-Service Physical Education Teachers' Discourses on Learning How to Become a Teacher: [Re]Constructing a Professional Identity Based on Visual Evidence.” The Open Sports Science Journal 7: 141-171.

Day, C. 2012. "New Lives of Teachers." Teacher Education Quarterly 39 (1): 7-26.

Day, C., and A. Kington. 2008. "Identity, Well-being and Effectiveness: The Emotional Contexts of Teaching." Pedagogy, Culture \& Society, 16 (1): 7-23. doi:10.1080/14681360701877743.

Dowling, F. 2006. “Physical Education Teacher Educators' Professional Identities, Continuing Professional Development and the Issue of Gender Equality.” Physical Education and Sport Pedagogy 11 (3): 247-263. doi:10.1080=17408980600986306. 
Dowling, F. 2011. “"Are PE Teacher Identities Fit for Postmodern Schools or Are They Clinging to Modernist Notions of Professionalism?' A Case Study of Norwegian PE Teacher Students' Emerging Professional Identities.” Sport, Education and Society 16 (2): 201-222. doi:10.1080/13573322.2011.540425.

Dowling, F., and S. Kårhus. 2011. “An Analysis of the Ideological Work of 'Fair Play’ and Moral Education in Perpetuating Inequitable Gender Practices in PETE.” Physical Education and Sport Pedagogy 16 (2): 197-211.

Doolittle, S., W. Li, P. B. Rukavina, M. Manson, and A. Beale. 2016. "Middle School Physical Education Teachers' Perspectives on Overweight Students.” Journal of Teaching in Physical Education 35 (2): 127-137.

Erickson, L. B., and S. Pinnegar. 2017. “Consequences of Personal Teaching Metaphors for Teacher Identity and Practice.” Teachers and Teaching 23 (1): 106-122. doi:10.1080/13540602.2016.1203774.

Eteläpelto, A., Vähäsantanen, K., and P. Hökkä. 2015. "How Do Novice Teachers in Finland Perceive Their Professional Agency?” Teachers and Teaching 21 (6): 660-680. doi:10.1080/13540602.2015.1044327.

Eteläpelto, A., Vähäsantanen, K., Hökkä, P. and S. Paloniemi. 2013. "What Is Agency? Conceptualizing Professional Agency at Work.” Educational Research Review 10: 45-65. doi:10.1016/j.edurev.2013.05.001.

Eteläpelto, A., Vähäsantanen, K., Hökkä, P., and S. Paloniemi. 2014. "Identity and Agency in Professional Learning." In International handbook of research in professional and practice-based learning, edited by Stephen Billett, Christian Harteis, and Hans Gruber, 645-672. London: Springer. doi:10.1007/978-94-017-8902-8_24.

Fernandez-Balboa, J.-M. 1997. "Physical Education Teacher Preparation in the Postmodern Era: Toward a Critical Pedagogy." In Critical Postmodernism in Human Movement, 
Physical Education, and Sport, edited by Juan-Miguel Fernandez-Balboa, 121-138. Albany: State University of New York.

Fernández-Balboa, J.-M. 2001. “Connections, Pedagogy and Professional Learning.” Teaching Education 12 (1): 103-118. doi:10.1080/10476210123847.

Finnish National Board on Research Integrity. 2009. Ethical Principles of Research in the Humanities and Social and Behavioural Sciences and Proposals for Ethical Review. Accessed November 10, 2018. http://www.tenk.fi/sites/tenk.fi/files/ethicalprinciples.pdf

Finnish National Agency for Education. 2014. Basic Education Curricula. Accessed October $21,2017$. http://oph.fi/english/curricula_and_qualifications/basic_education/curricula_2014.

Fisette, J. L. 2015. “The Stigmatized Physical Educator.” Qualitative Research in Sport, Exercise and Health 7 (4): 466-487. doi:10.1080/2159676X.2014.981574.

Fletcher, T. 2012. "Experiences and Identities: Pre-service Elementary Classroom Teachers Being and Becoming Teachers of Physical Education.” European Physical Education Review 18 (3): 380-395. doi:10.1177/1356336X12450798.

Garrett, R., and A. Wrench. 2012. "'Society Has Taught Us to Judge': Cultures of the Body in Teacher Education.” Asia-Pacific Journal of Teacher Education 40 (2): 111-126. doi:10.1080/13573322.2011.607909.

González-Calvo, G. and J.-M. Fernández-Balboa. 2018. “A Qualitative Analysis of the Factors Determining the Quality of Relations between a Novice Physical Education Teacher and His Students' Families: Implications for the Development of Professional Identity." Sport, Education and Society 23 (6): 491-504. doi:10.1080/13573322.2016.1208164. 
Hökkä, P., and A. Eteläpelto. 2014. ”Seeking New Perspectives on the Development of Teacher Education: A Study of the Finnish Context." Journal of Teacher Education 65 (1): 39-52. doi:10.1177/0022487113504220.

Izadinia, M. 2013. “A Review of Research on Student Teachers’ Professional Identity.” British Educational Research Journal 39 (4): 694-713. doi:10.1080/01411926.2011.620602.

Johnson, T. G. 2015. “Lived Body Knowledge: Disciplinary Knowledge for Preservice Physical Education Teachers." Quest 67 (2): 227-239. doi:10.1080/00336297.2015.1017589.

Kalaja, T. 2012. "Liikunnan aineenopettajakoulutuksen opiskelijavalinnat muutoksessa." PhD diss., University of Jyväskylä. https://jyx.jyu.fi/dspace/bitstream/handle/123456789/37936/9789513947415.pdf?sequ ence $=1$

Keating, X. D., J. Liu, Y. Fan, K. Zhou, R. Shangguan, and L. Harrison. 2017. "Research on Preservice Physical Education Teachers' and Preservice Elementary Teachers' Physical Education Identities: A Systematic Review." Journal of Teaching in Physical Education 36 (2): 162-173. https://doi.org/10.1123/jtpe.2016-0128

Kirk, D., D. MacDonald, and R. Tinning. 1997. "The Social Construction of Pedagogic Discourse in Physical Education Teacher Education in Australia." The Curriculum Journal 8 (2): 271-298. doi:10.1080/0958517970080206.

Larsson, L. 2009. “Idrott - och helst lite mer idrott: Idrottslärarstudenters möte med utbildningen.” PhD diss., Stockholm University. (Unpublished doctoral dissertation). http://www.diva-portal.org/smash/get/diva2:234649/FULLTEXT01.pdf 
Lamote, C., and N. Engels. 2010. “The Development of Student Teachers' Professional Identity.” European Journal of Teacher Education 33 (1): 3-18. doi:10.1080/02619760903457735.

MacDonald, D. 1993. "Knowledge, Gender and Power in Physical Education Teacher Education.” Australian Journal of Education 37 (3): 259-278.

Murray, J., A. Swennen, and L. Shagrir. 2009. “Understanding Teacher Educators’ Work and Identities.” In Becoming a Teacher Educator, edited by Anja Swennen and Marcel van der Klink, 29-43. Dordrecht: Springer.

Ó Gallchóir, C., J. O’Flaherty, and C. Hinchion. 2018. “Identity Development: What I Notice about Myself as a Teacher.” European Journal of Teacher Education 41 (2): 138156. doi:10.1080/02619768.2017.1416087.

Patton, M. Q. 2002. Qualitative Research \& Evaluation Methods. 3rd ed. London: Sage.

Pappa, S., Moate, J., Ruohotie-Lyhty, M., and A. Eteläpelto. 2017. “Teachers’ Pedagogical and Relational Identity Negotiation in the Finnish CLIL Context." Teaching and Teacher Education 65: 61-70. doi:10.1016/j.tate.2017.03.008.

Pillen, M., D. Beijaard, and P. den Brok. 2013a. "Tensions in Beginning Teachers' Professional Identity Development, Accompanying Feelings and Coping Strategies.” European Journal of Teacher Education 36 (3): 240-260. doi:10.1080/02619768.2012.696192.

Popper-Giveon, A., and B. Shayshon. 2017. "Educator versus Subject Matter Teacher: The Conflict between Two Sub-Identities in Becoming a Teacher.” Teachers and Teaching 23 (5): 532-548. doi:10.1080/13540602.2016.1218841.

Ramos, N. C., and B. A. McCullick. 2015. "Elementary Students' Construct of Physical Education Teacher Credibility.” Journal of Teaching in Physical Education 34 (4): 560-575. http://dx.doi.org/10.1123/jtpe.2014-0052 
Ruohotie-Lyhty, M., and J. Moate. 2016. "Who and How? Preservice Teachers as Active Agents Developing Professional Identity.” Teaching and Teacher Education 55: 318 327. doi:10.1016/j.tate.2016.01.022

Simola, H., J. Kauko, J. Varjo, M. Kalalahti, and F. Sahlström. 2017. Dynamics in Education Politics: Understanding and Explaining the Finnish Case. London: Routledge.

Sirna, K., R. Tinning, and T. Rossi. 2010. "Social Processes of Health and Physical Education Teachers' Identity Formation: Reproducing and Changing Culture.” British Journal of Sociology of Education 31 (1): 71-84. doi:10.1080/01425690903385501.

Spittle, M., F. Petering, P. Kremer, and S. Spittle. 2012. "Stereotypes and Self-Perceptions of Physical Education Pre-service Teachers.” Australian Journal of Teacher Education 37 (1): 18-42. doi:10.14221/ajte.2012v37n1.5.

Thomas, L., and C. Beauchamp. 2011. “Understanding New Teachers' Professional Identities through Metaphor.” Teaching and Teacher Education 27 (4): 762-769. doi:10.1016/j.tate.2010.12.007.

Thorburn, M. 2014. “'It Was the Best of Times, It Was the . . ': Subject Aims and Professional Identity from the Perspective of One Veteran Male Teacher of Physical Education in Scotland." Teachers and Teaching: Theory and Practice 20 (4): 440452. doi:10.1080/13540602.2014.881641.

Tinning, R. 2010. Pedagogy and Human Movement: Theory, Practice, Research. London: Routledge.

Tinning, R., and T. Glasby. 2002. "Pedagogical Work and the 'Cult of the Body': Considering the Role of HPE in the Context of the 'New Public Health.'" Sport, Education and Society 7 (2): 109-119. doi:10.1080/1357332022000018814 
Vähäsantanen, K. 2015. "Professional Agency in the Stream of Change: Understanding Educational Change and Teachers' Professional Identities." Teaching and Teacher Education 47: 1-12. doi:10.1016/j.tate.2014.11.006.

Vähäsantanen, K., Hökkä, P., Eteläpelto, A., Rasku-Puttonen, H., and K. Littleton. 2008. “Teachers' Professional Identity Negotiations in Two Different Work Organisations." Vocations and Learning 1 (2): 131-148. doi:10.1007/s12186-008-9008-z.

Webb, L., M. Quennerstedt, and M. Öhman. 2008. "Healthy Bodies: Construction of the Body and Health in Physical Education." Sport, Education and Society 13 (4): 353372. doi:10.1080/13573320802444960.

Weiner, J. M., and A. C. Torres. 2016. "Different Location or Different Map? Investigating Charter School Teachers' Professional Identities." Teaching and Teacher Education 53: 75-86. doi:10.1016/j.tate.2015.11.006.

Wrench, A. 2017. “Spaces and Physical Education Pre-service Teachers' Narrative Identities." Sport, Education and Society 22 (7): 825-838. doi:10.1080/13573322.2015.1094046.

Wrench, A., and R. Garrett. 2012. "Identity Work: Stories Told in Learning to Teach Physical Education.” Sport, Education and Society 17 (1): 1-19. doi:10.1080/13573322.2011.607909.

Wrench, A., and R. Garrett. 2015. "PE: It's Just Me: Physically Active and Healthy Teacher Bodies.” International Journal of Qualitative Studies in Education 28 (1): 72-91. doi:10.1080/09518398.2013.855342.

Wright, J. 2000. "Bodies, Meanings and Movement: A Comparison of the Language of a Physical Education Lesson and a Feldenkrais Movement Class.” Sport, Education and Society 5 (1): 35-49. doi:10.1080/135733200114424. 